\title{
A arte-educação no ensino médio: desafios à formação estética
}

\author{
Rafaella Lira de Vasconcelos* \\ Universidade de Brasília \\ Catia Piccolo Viero Devechi** \\ Universidade de Brasília
}

Resumo $\mathrm{O}$ artigo busca compreender e refletir, por meio de uma abordagem hermenêutica, a atuação do arte-educador do ensino médio diante das condicionantes da sociedade administrada, a partir das percepções dos professores de arte das escolas públicas do Distrito Federal. Para tal foi aplicado um questionário para identificar os desafios desses profissionais nas suas práticas de ensino, por exemplo as poucas horas-aula destinadas às aulas de arte, a incompatibilidade entre a formação específica do arte-educador na graduação e seu exercício polivalente na sala de aula e o não reconhecimento do trabalho em arte-educação perante seus pares e a sociedade. Os dados são discutidos a partir da teoria estética de Adorno (2008), que aponta a potencialidade crítica da arte e seu compromisso social na contemporaneidade. Estima-se que, em uma perspectiva estética, a arte no ensino médio poderia se colocar como um espaço de formação para o espírito humano, em que a sensibilidade crítica não estivesse contra a ciência, mas vislumbrada como pertencente à integralidade do indivíduo e como forma de resistência diante da massificação sociocultural.

PALAVRAS-CHAVE: Formação estética; Arte-educador; Sociedade administrada. 
The art-education in middle school: challenges and faces to aesthetic formation

Abstract The article seeks to understand and reflect, through a hermeneutic approach, the performance of the art-educator of High School in the face of the conditions of the society managed, based on the perceptions of the art teachers of the public schools of the Federal District. For this purpose a questionnaire was applied to identify the challenges of these professionals in their teaching practices, such as the few hoursclasses for art classes, the incompatibility between the specific training of the art-educator in the undergraduate and his multipurpose exercise in classroom and the non-recognition of art-education work vis-à-vis peers and society. The data are discussed from the aesthetic theory of Adorno (2008) that points out the critical potentiality of art and its social commitment in contemporaneity. We believe that, from an aesthetic perspective, art in High School could be seen as a space of formation for the human spirit, in which the critical sensibility was not against science, but glimpsed as belonging to the integrality of the individual and as a form of resistance of sociocultural massification.

KEYWORDS: Aesthetic formation; Art-educator; Managed company.

\section{Considerações iniciais}

Em tempos de crise da formação humana, a sensibilidade, as relações éticas dos indivíduos e das sociedades, o reconhecimento do outro e a busca de uma razão emancipada são colonizados pela instrumentalidade do saber, sendo ela fruto das imposições do esclarecimento em que a promessa de felicidade, progresso e liberdade não se cumpriu. Temos vivenciado um momento caótico e desigual, impregnado de barbáries, conflitos em detrimento da alteridade, das experiências estéticas, da formação crítica e da educação humanizada. O que parece importar é o preparo dos sujeitos para competir diante das exigências do mercado de trabalho somado a uma formação cultural reduzida à semiformação, entendida por Adorno (2010, p. 25) como "o espírito conquistado pelo fetiche da mercadoria", isto é, uma distorção da cultura enquanto contribuição à formação dos indivíduos em e pelas ideias de consumo disseminadas pela indústria cultural.

Trata-se de uma perspectiva de vida massificada em que as relações de dominação econômica e cultural têm tomado o espaço do cotidiano escolar, não sendo diferente no ensino de arte, que vem perdendo espaço nos currículos em favor de uma educação tecnificada. Nesse caminho, faz-se necessário atentar para o fato de que a educação e os processos escolares não são capazes de garantir, em si mesmos, a autonomia para se emancipar dessas relações. Segundo Adorno (1995), devemos cuidar para o duplo caráter da educação, pois, ao passo que ela busca esclarecer e refutar a subjugação, também pode se colocar como ferramenta de adaptação social. Nesse sentido, diz que "é necessário romper com a educação enquanto mera apropriação de instrumental 
técnico e receituário para a eficiência, insistindo no aprendizado aberto à elaboração da história e ao contato com o outro não idêntico, o diferente" (ADORNO, 1995, p. 27). É nesse jogo de resistência que o autor credita à estética uma possibilidade de acesso à emancipação, dado que a arte pode se conectar ao que não lhe é congênere, perceber o não idêntico (ADORNO, 2008) e também contrapor a objetivação e a padronização dos seres.

Em diálogo com Becker (debate transmitido pela Rádio de Hessen na Alemanha em 26 de setembro de 1966 e intitulado "Educação - para quê?"), Adorno (1995) discorre sobre os malefícios do declínio humano para a experiência formativa e enfatiza que essa incapacidade é advinda da pressão de um mundo objetivado e persistente na adaptação dos indivíduos ao seu caráter afirmativo. Engendrado em pensar sobre a resistência a esse sistema, o autor reitera que a crítica desse realismo é uma das tarefas mais importantes do processo educacional.

Diante dessas considerações, buscamos discutir os desafios da arte no ensino médio, bem como as percepções, as inquietações e as vozes dos arte-educadores ${ }^{1}$, levando em conta as demandas atuais dessa etapa de ensino. Para tanto, utilizamo-nos dos dados alcançados em uma pesquisa realizada na Universidade de Brasília com os arte-educadores atuantes no ensino médio da Secretaria de Estado de Educação do Distrito Federal (SEEDF), selecionados a partir de dois critérios: i) serem professores efetivos da SEEDF; ii) lecionarem em escolas que atendem exclusivamente essa fase do ensino regular em Brasília. Tais escolas recebem estudantes residentes em todo o Distrito Federal e cidades do Entorno. Isso lhes confere uma diversidade cultural, econômica e geográfica. Segundo Castro (2013), Brasília é composta por um traçado diferenciado não apenas no sentido de sua arquitetura, mas dos aspectos socioeconômicos e culturais. Para as crianças e adolescentes que se deslocam diariamente de suas cidades para estudar na Capital do país, esses traços se desmancham no caminho de volta para casa. Pensando nessas multiplicidades e nos desafios que essas contradições podem impor ao trabalho do arte-educador foi que optamos por escolas de Brasília. Dentro dos critérios estabelecidos, localizamos cinco escolas, totalizando quatorze professores, dos quais onze se dispuseram a colaborar com a pesquisa; e, desses, sete contribuíram efetivamente.

Enviamos aos professores um questionário com questões abertas e fechadas por meio do endereço de e-mail e/ou Facebook através da ferramenta Google Drive, do Gmail. O questionário ficou disponível para os respondentes por dois meses (setembro e outubro de 2015). As perguntas do questionário versavam principalmente sobre as percepções dos arte-educadores acerca de suas formações e realidades de atuação docente; a respeito de seus entendimentos do conceito de formação estética; suas opiniões relativas às orientações do Currículo em Movimento do Ensino Médio da Secretaria de Estado de Educação do Distrito Federal ${ }^{2}$ e as suas possibilidades de efetivação nas práticas docentes; e, por fim, questões quanto as percepções dos arteeducadores em relação ao ensino da arte.

A partir dos dados produzidos, separamos os desafios que mais se destacaram nas respostas dos arte-educadores e analisamos por meio da abordagem herme- 
nêutico-filosófica de Gadamer (1983). A análise não pretendeu conferir ou fundamentar uma verdade única e insuperável, mas compreender como os sujeitos envolvidos (arte-educadores) se articulam, o porquê da manifestação de determinados propósitos, disposições e conceitos diante do compromisso da arte no ensino médio. Antes de apresentarmos os desafios, expomos a compreensão estética de Adorno (2008), que aponta a potencialidade crítica da arte e seu compromisso social diante da sociedade administrada, que será o fundamento teórico das nossas análises.

\section{Formação estética versus sociedade administrada}

Os filósofos Adorno e Horkheimer realizaram na obra Dialética do Esclarecimento - publicada pela primeira vez em 1947 - um debate sobre o conceito de esclarecimento na sociedade atual. Os autores nos reportam à mitologia como uma analogia aos intentos do chamado "homem moderno". Segundo eles, a procura pela libertação da sensibilidade e da dependência das crenças conduziu esse homem pelos caminhos do esclarecimento como uma promessa de emancipação baseada em uma racionalidade dotada de progresso e autonomia. No entanto, afirmam: "a maldição do progresso irrefreável é a irrefreável regressão” (ADORNO; HORKHEIMER, 1985, p. 41). Para que a sociedade solidificasse sua identidade, já não mais pautada no mito, nas crenças e no senso comum, foi preciso imprimir um caráter de igualdade e de ascensão do espírito entre os indivíduos. Assim, no traçado dessa linha ambivalente, os autores apontam que a civilização esclarecida caminhava para uma forma de dominação social que não se contentou com a repressão da animalidade e do encantamento mitológico, mas perscrutou a constituição de uma estrutura arquitetada para a manutenção e o desenvolvimento do capital, também para o rigor dos tabus e para a reprodução estereotipada dos comportamentos e da arte por meio da indústria cultural. Esta, por sua vez, responsabilizou-se pela massificação do esclarecimento e pela manipulação das reflexões.

Ao prosseguirmos no entendimento das estruturas sociais, reportamo-nos ao texto adorniano intitulado Teoria da Semiformação (2010). Nesse texto, o autor explana a impossibilidade de essa forma de propagação cultural contribuir para a formação dos indivíduos, incutindo-nos a pensar que a indústria cultural é uma propagadora da semiformação e é também um dos pilares de sustentação da sociedade atual. $\mathrm{Na}$ obra Educação e Emancipação (1995), Adorno definiu a sociedade atual como uma sociedade administrada, dotada de aspectos afirmativos e objetivados para a reificação da humanidade. Segundo ele, tal sociedade tem planos bem arquitetados para a sociedade no que se refere ao âmbito político, econômico, cultural e educacional, estando as nossas condições de vida, trabalho e consumo cerceadas por uma objetividade que visa a nos projetar para uma massa amorfa (ADORNO, 1995). A razão esclarecida do projeto moderno é convertida em razão objetivada e a humanidade regredida à barbárie, à insensibilidade, ao não reconhecimento do outro, à descrença humana e ética e à reificação da vida.

Mediante a crise de formação cultural deformadora dos indivíduos sociais e de suas relações, Adorno percebe um grande entrave da formação no sentido da Bildung? , pois para ele "a formação devia ser aquela que dissesse respeito - de uma 
maneira pura como seu próprio espírito - ao indivíduo livre e radicado em sua própria consciência" (ADORNO, 1996, p. 11). Se estamos impedidos pelos aspectos semiformativos e embrutecidos pela sociedade administrada, como negaremos este estado disforme? Segundo Adorno, a estética, por meio das obras de arte, pode ser um recurso de negação, pois permite que os indivíduos enxerguem além do véu do esclarecimento, estabelecendo-se como uma razão interpretativa que provém do vivente empírico e retorna para o social como uma recusa, uma antítese (ADORNO, 2008). É nesse movimento de negação, reflexão e dialética que o autor percebe na dimensão estética uma vicissitude formativa capaz de se contrapor à reificação da sociedade administrada e de permitir a emancipação.

Na obra Teoria Estética (2008), publicada postumamente, Adorno diz que a arte, enquanto experiência estética, tem potencial de contraposição da realidade. Por ser autônoma, não se deixa imitar pela realidade, mas, pelo contrário, à denúncia. Percebe na arte autêntica um potencial de liberdade e de transformação social. Alerta, entretanto, para os perigos da arte reificada em mercadoria pela indústria cultural. Diz ele:

Da autonomia da arte, que suscita a cólera dos consumidores da cultura, pelo fato de considerarem as obras algo melhor do que eles creem ser, resta apenas o carácter fetichista das mercadorias, regressão ao fetichismo arcaico na origem da arte: nesta medida o comportamento contemporâneo perante a arte é regressivo. Nas mercadorias culturais consome-se o seu ser-para-outro abstrato, sem que elas sejam verdadeiramente para os outros; na medida em que lhes estão ao serviço, enganam-nos. A antiga afinidade de contemplador-contemplado é invertida (ADORNO, 2008, p. 35).

A compreensão de Adorno é que, diante da indústria cultural, a arte se transformou em "coisa", fortalecendo a imitação alienada do real. Por isso, chama a atenção para a necessidade de retomar a sua imanência crítica, resistindo a ordem social colocada. Mesmo resultando do mundo histórico-social, a arte deve buscar sempre transformá-lo. Percebe na experiência estética uma importante forma de racionalidade, tendo em vista o seu potencial de reflexão sobre a realidade. Pelo seu caráter autônomo e libertador, é capaz de representar o conhecimento sem dominação e sem violência, por isso há necessidade de a educação permitir, por meio da arte, experiências estéticas, evitando a reprodução tecnificada da aprendizagem e a semiformação.

Se para Adorno a formação só é possível aos emancipados em sua própria consciência, pensar a educação como um processo de libertação exige de nós - pesquisadores/educadores - uma vigilância rotineira a fim de que não sejamos propagadores dos mecanismos do pseudoesclarecimento e da subjugação. Para colaborarmos com os processos formativos, necessitamos estar atentos às estruturas educacionais em sua completude e complexidade, o que requer que estejamos precavidos de crítica para compreendermos os diversos prismas dos fatos políticos, econômicos e sociais. Recentemente, assistimos à capacidade de denúncia da arte através do desfile da escola de samba Paraíso do Tuiuti, realizado durante o Carnaval no Sambódromo da Marquês de Sapucaí, na cidade do Rio de Janeiro. A apresentação utilizou-se da estética, por meio de diversas linguagens artísticas, tais como a música e a performance, para evi- 
denciar as problemáticas latentes no Brasil: o conturbado impeachment presidencial e as controvérsias acerca da reforma da Previdência trabalhista. Já na contramão dessa viabilidade de indagação, observamos muitas polêmicas em torno da arte e sua difusão na sociedade brasileira, a exemplo das performances envolvendo nudez em espaços públicos, em museus e exposições de obras de arte que estão sendo censuradas sem debates e questionamentos pautados em uma reflexão estética e crítica. Segundo Adorno (2008, p. 296), "no juízo da história, a dominação como opinião dominante cruza-se com o desenvolvimento da verdade das obras". Assim, podemos apreender que os fatos envolvendo a arte e a sociedade não podem ser analisados isoladamente, pois há neles contextos de poder e controle que parecem imbricados. Isso posto, não observamos a disposição da discussão sobre a arte decorrente da indústria cultural que tem levado a comportamentos sociais incompatíveis com uma vida social emancipada.

Desse modo, entendemos que a arte precisa se alicerçar em uma dimensão crítica de modo a evitar qualquer tipo de manipulação, seja econômica, social ou política. Segundo Adorno (2008, p. 132), "a arte transforma-se em ideologia ao sugerir, como imago do não cambiável, a ideia de que no mundo nem tudo seria permutável. Em virtude do não cambiável, ela deve, através da sua forma, levar o cambiável à autoconsciência crítica".

\section{Os desafios dos arte-educadores no ensino médio}

$\mathrm{Na}$ pesquisa realizada com os arte-educadores do ensino médio em Brasília - DF, identificamos alguns desafios, que a nosso ver terão de ser enfrentados. Nesse artigo, apresentamos os desafios que mais se destacaram na pesquisa que categorizamos da seguinte forma: as problemáticas com a carga horária da disciplina e dos professores de arte na escola; a precarização do sistema educacional, que colabora com o desinteresse dos estudantes; a falta de reconhecimento da tarefa desses professores, bem como da própria arte enquanto elemento crítico para a formação dos indivíduos na sociedade; e, por fim, a questão da polivalência na atuação pedagógica do arte educador. Tais desafios são apresentados a seguir.

\section{Carga horária da disciplina e dos arte-educadores na escola}

Constatamos, na nossa pesquisa, que é unânime entre os arte-educadores o desafio relativo à carga horária da disciplina e à sua carga de trabalho imbricada. Nesse ínterim podemos destacar duas dimensões citadas pelos professores: a primeira delas diz respeito às poucas horas-aula em cada turma, que representam em média duas aulas semanais com duração de cinquenta minutos cada. O número de horas-aula demonstra a disparidade incutida na relação da arte com as demais disciplinas, que, de modo geral, apresentam maior carga horária na grade curricular, caracterizando o pouco interesse do Estado na formação da sensibilidade crítica dos estudantes. Segundo Pucci (2001, p. 7), o Estado propicia "condições para o desenvolvimento de uma educação semiformativa, utilizando-se da escola, mais uma vez, para favorecer os interesses dos grupos hegemônicos da sociedade". Dessa maneira, o tempo e o espaço que poderiam auxiliar para a formação de uma razão crítica e sensível dos discentes é convertido em um momento de adaptação à sociedade administrada. Essa dimensão 
reitera as ideias de Tourinho (2012, p. 32), quando afirma que há uma longa história de luta da arte e de outras disciplinas "pela conquista de espaço e, segundo, pela manutenção e ampliação desse espaço e tempo na escola". A autora destaca que essas lutas se constituem como um jogo e de algum modo representam interesses ideológicos de determinados grupos, contudo não são compreendidas na totalidade pela sociedade e, por isso, se justificam por aquilo que podem representar de imediato à vida dos estudantes. Assim, o ensino de arte e o arte-educador estão sempre impelidos a provar sua contribuição educativa de modo quase abrupto. Para Adorno (1996, p. 407), esse é mais um sintoma da cultura degenerada, pois "o semiculto transforma, como que por encanto, tudo que é mediato em imediato, o que inclui até o que mais distante é." Este encalço torna o ensino de arte ainda mais questionável, pois dificulta que o trabalho do arte-educador se desenvolva diante de suas potencialidades.

A segunda dimensão refere-se à carga de trabalho destinada aos professores de arte. Cada docente tem em média quinze turmas para lecionar, ou seja, de modo geral ele é o único professor de arte de um dos turnos na escola. Essa sobrecarga, além de o levar a um esgotamento físico e intelectual, acaba por precarizar o trabalho e sua formação continuada. Devido à grande quantia de turmas, o professor tem de repetir sua aula por diversas vezes na semana em diferentes turmas de um mesmo ano do ensino médio. Além disso, há outros trabalhos que também precisam ser cumpridos por esse professor, tais como o preenchimento da frequência diária dos estudantes e dos campos de conteúdo e notas dos diários de classes. A repetição do trabalho docente remonta aos moldes da sociedade industrializada, contudo não eleva a qualidade educativa, ao contrário, paralisa-se a criação do pensamento. Segundo Neuvald e Guilhermeti (2016, p. 3) "ao imobilizar a autorreflexão do espírito, afasta-se de sua dimensão filosófica, que pressupõe a tensão, o risco e a perturbação". Essa inércia reforça as dificuldades de desenvolver a arte em sua potencialidade, objetificando o trabalho do arte-educador.

\section{Precarização do sistema educacional e desinteresse dos estudantes}

A falência e a precarização do sistema educacional, bem como o desinteresse dos discentes, também são apontadas como desafio ao ensino de arte no ensino médio. Os professores investigados alertaram para a precariedade do sistema público brasileiro como um dos causadores do desinteresse dos estudantes durante as aulas de arte. Segundo eles, faltam materiais como recursos audiovisuais, por exemplo, sendo o próprio espaço físico da sala de aula desestimulante. Sobre essa avidez por ferramentas mais atuais da tecnologia em sala de aula, Pucci (2009) nos alerta para o fato de que vivemos um tempo de realidades virtuais, de mundos fictícios, em que a máquina é sinônimo de eficiência e modernidade, o que acarreta descrença em relação ao trabalho humano. Isso traz à atividade do professor uma sensação de impotência, pois a tecnologização da educação é o que parece ser a salvaguarda, contudo nos aproxima ainda mais do instrumentalismo. Em certa medida, precisamos analisar que no ensino de arte não é possível rejeitarmos totalmente os usos dessas ferramentas, pois, como diz Pimentel (2012, p. 135), "o uso de novas tecnologias possibilita aos alunos desen- 
volver sua capacidade de pensar e fazer arte contemporaneamente, representando um importante componente da vida dos alunos e professores".

Concomitante ao desinteresse pelas aulas de arte, que pode estar relacionado a esse cenário do aparato tecnológico instrumentalizado, os educadores apontam como desafio a pouca capacidade de fruição estética dos discentes. Ao traçarmos uma breve análise histórica do ensino de arte, observamos que a disciplina não se constituiu como prioridade nas pautas legislativas. Somente no ano de 1971, por meio da Lei de Diretrizes e Bases da Educação Nacional, é que o ensino de arte se instituiu como atividade curricular e não apresentava contornos consistentes com prerrogativas de uma disciplina. Desde esse período a área carrega uma prática diluída (FUSARI; FERRAZ, 2001), pois a disciplina nunca foi obrigatória em todas as etapas de ensino da educação básica. Na educação infantil e nos anos iniciais do ensino fundamental, apesar das orientações legais ao trabalho com as linguagens da arte, essa não é uma incumbência de um professor especialista e portanto parece não haver uma educação do sensível satisfatória nessas fases. Nos anos finais do ensino fundamental, os estudantes têm em média apenas uma aula de arte semanal, com duração de cinquenta minutos. Podemos dizer que a insuficiência de uma educação estética durante a vida escolar dos estudantes justifica a falta de experiência e gosto pela arte. Segundo Trevisan (2000, p. 98), "se os processos de conhecimento e aprendizagem perdem a sua referência à arte e à alta cultura, recaem na imitação vulgarizada, desfigurada, da escola reprodutiva, sem graça, sem choques e sem quebra de rotina". O trajeto que os discentes realizam antes de chegarem ao ensino médio público é um caminho com poucas alternativas às questões da estética. Farina e Albernaz (2017, p. 118) concebem que "la formación estética se da mediante la diversidad de imágenes, performances y discursos que la sostienen y que pueblan su cotidiano". Destarte, uma educação para o sentido formativo do sensível que ajude na superação dessa precariedade educacional carece de um solo com mais possibilidades para o desenvolvimento de estudos reflexivos, críticos, historiados no contexto social e que propicie uma racionalidade estética, tanto para os estudantes quanto para os arte-educadores.

\section{A falta de reconhecimento da tarefa do arte-educador na} escola

A incompreensão dos docentes de outras disciplinas sobre a importância das atividades relativas à arte na escola foi descrita como uma situação problemática e desafiadora pelos arte-educadores, pois faz com que as propostas aos projetos interdisciplinares que visam a ampliar o tempo e as oportunidades do trabalho em arte muitas vezes sejam limitadas por essa falta de reconhecimento dos saberes relativos à arte-educação. Barbosa (1989) já apontava que, mesmo em um período marcado pela redemocratização do país, havia pelo menos duas causas para tamanho preconceito com o ensino de arte no Brasil: o entendimento de que esse ensino era ineficiente, pois os professores não tinham formação específica e os cursos de graduação em arte ainda estavam em processo de estruturação; e a crença de que o país precisava crescer e se recuperar em aspectos de conteúdo. Tendo em vista que o ensino de arte não era compreendido como disciplina, mas como uma atividade, suas contribuições não eram 
interessantes para o momento político. Ao confrontarmos as reflexões de Barbosa com os dias atuais, percebemos que os impasses são muito semelhantes e que os motivos para a banalização da arte-educação perduram. Segundo Conte (2014, p. 548)

\begin{abstract}
Embora os tempos atuais exijam seguidamente uma presença cada vez maior da reflexão filosófica, artística e pedagógica, é notório que esses espaços têm paulatinamente perdido o seu vínculo com a cultura geral. Parece que a aceleração do tempo desestabiliza o empenho ético e a alegria de aprender, pela vigência da temporalidade institucionalmente organizada e confundida com a competitividade, que provoca um encolhimento de ações solidárias à construção de uma intersubjetividade democrática.
\end{abstract}

$\mathrm{O}$ arte-educador deve ter a preocupação de levantar debates a que outras áreas do conhecimento geralmente não se dispõem. No entanto, de acordo com esses educadores, docentes dessas outras áreas não se predispõem a interagir e auxiliar com essas propostas e também se manifestam inflexíveis para o diálogo. Acerca do não reconhecimento dos indivíduos, podemos destacar a tese de Honneth (2003) sobre questões de reconhecimento e conflito. $\mathrm{O}$ autor concebe o desrespeito e o não reconhecimento ao outro como uma patologia da sociedade contemporânea e entende essa característica como um impedimento à formação do indivíduo, pois para ele só se pode chegar a uma autorrelação bem-sucedida através do reconhecimento intersubjetivo de nossas capacidades e realizações. Sobre isso, Cenci, Dalbosco e Muhl (2014, p. 225) argumentam que um dos principais desafios da problemática do reconhecimento "é conciliar o respeito às diferenças e às singularidades de indivíduos e grupos, típicas de sociedades pluralistas, com a exigência de igualdade e universalidade consolidada pela herança iluminista moderna". Os autores destacam que a luta pelo reconhecimento intersubjetivo também perpassa o conflito, e essa perspectiva do tensionamento "pode servir como ponto de partida para a discussão de processos formativos em perspectiva emancipatória" (CENCI; DALBOSCO; MUHL 2014, p. 236). Assim, apesar de a situação relatada pelos arte-educadores motivar um ambiente de enfrentamento que, quando não superado, prejudica e degenera não apenas as relações profissionais no que se refere ao ensino da disciplina, mas também as relações intersubjetivas mais complexas, este pode ser também um caminho esperançoso para um ambiente favorável, respeitoso e criador.

\title{
A relação arte e sociedade
}

Podemos dizer que a relação de segregação entre arte e sociedade apontada pelos professores como uma contenda à arte-educação é uma ramificação do não reconhecimento da função do arte-educador na escola. Na sociedade do imediato, da valorização de disciplinas estanques em detrimento de outras, no mundo do preparo massivo para o mercado de trabalho, os estudantes acabam por não se relacionar com arte em outros âmbitos sociais que não aqueles dispostos para o consumo, que são, na maioria das vezes, acríticos e servem à manutenção da sociedade administrada. Para os arte-educadores, a arte ainda é marginalizada no contexto social; e, mesmo com as possibilidades de acesso à informação e aos meios artísticos, o que prevalece são as ofertas da indústria cultural. Inferimos aqui o pensamento de Adorno na Teoria 
Estética sobre a relação entre arte e identidade estética e sociedade. Para o autor, "a identidade estética deve defender o não idêntico que a compulsão à identidade oprime na realidade" (ADORNO, 2008, p. 16). Dessa afirmação, suscitamos que a arte em seu caráter crítico não desperta interesse imediato como uma obra fabril, uma vez que os aspectos de equivalência e identificação vão ao encontro do despreparo estético consequente da semiformação. O conteúdo de verdade de uma obra de arte é o seu próprio aspecto crítico, questionador, inconformista e, portanto, não é algo que se identifica imediatamente, mas exige mediação e crítica (ADORNO, 2008).

Diferentemente do espaço e tempo de reflexão que a obra de arte reivindica, as mídias e os recursos da era digital nos conduzem a certo ponto que vai direto aos seus objetivos, não nos restando muito fôlego para recuar, senão pelo exercício do pensamento filosófico. Se as aulas de arte têm um curto horário na grade curricular, os professores estão exaustos e as investidas de formação estética na educação básica são descontínuas, parece inerente que haja uma barreira na tentativa de aproximação entre arte e sociedade. Essa dinâmica torna o corpo social cada vez mais enrijecido, de modo que "a dança, a festa, a arte, o ritual são afastados de nosso cotidiano, que vai sendo preenchido com o trabalho utilitário, não criativo, alienante" (DUARTE JÚNIOR, 2012, p. 64). Assim, a luta pelo reconhecimento do trabalho em arte-educação frente aos estudantes e à sociedade pode se intensificar, na medida em que ofereça resistência à semiformação.

\title{
A polivalência no ensino de arte
}

A polivalência no ensino de arte é outro desafio resultante da incompatibilidade entre a formação nos cursos de graduação em Teatro, Artes Visuais, Música ou Dança e a atuação docente do arte-educador. Segundo Magalhães (2002, p. 162):

\begin{abstract}
A polivalência - conhecimento superficial em todas as linguagens artísticas - enquanto proposta metodológica evidenciada no ensino-aprendizagem em arte revelou-se/revela-se ineficaz para uma formação generalista que não correspondeu/corresponde ao profissional que se pretende formar, com competência para atender às diversas realidades dos contextos culturais brasileiros e às tendências contemporâneas advindas da tecnologia. É evidente que esta proposta metodológica deixou sérias lacunas na formação do professor e nas práticas educativas em arte, que contribuíram para a superficialidade da área nos currículos escolares e impossibilitaram o conhecimento sistematizado, sua contextualização histórica e a especificidade de cada linguagem artística.
\end{abstract}

Diante de uma diversidade de conteúdos apresentados no Currículo em Movimento para o Ensino Médio da SEEDF, relativos às diferentes linguagens da arte a serem tratadas em sala de aula, que não abrangem somente a formação inicial docente nessas linguagens (Teatro, Artes Visuais, Música ou Dança), o professor se vê provocado a buscar formas de complementar seus conhecimentos que não são gerais e, muitas das vezes, utilizando-se da internet como recurso de informação aligeirado, insuficiente para o ensino de arte em uma perspectiva estética. Essa problemática, apesar de pertinente, é ainda ofuscada, pois ela existe somente no mundo da prática docente 
do arte-educador, uma vez que, para os pareceres legais que norteiam os cursos de formação inicial, esse não é um problema materializado, pois preconizam que "a formação em curso superior contemple a especificidade das linguagens artísticas - e não mais a polivalência e a generalidade" (BRASIL, 2007, p. 3).

Podemos dizer que os cursos de graduação em arte no Brasil e o ensino de arte nas escolas públicas de ensino médio do Distrito Federal trilham caminhos divergentes, pois, ao passo que a formação em nível superior busca abranger as especificidades das linguagens artísticas em acordo com as Diretrizes Curriculares Nacionais (DCN) dos cursos de graduação em artes (Música, Dança e Teatro) aprovadas em 2004 e com as DCN do curso de graduação em Artes Visuais aprovadas em 2009, as escolas são expostas a uma estrutura curricular que se apresenta como interdisciplinar e se efetiva como polivalente. $\mathrm{Na}$ prática, essa estrutura não pode atender à interdisciplinaridade, porque não há quadro de pessoal efetivo para suprir a demanda das especificidades de cada uma das linguagens abordadas no currículo, e também não há uma organização nem proposições para que isso venha a se concretizar prontamente. Desse modo, o modelo curricular para o ensino de arte e a efetivação na prática indicam o seu aspecto instrumental. A autodeclaração dos arte-educadores como professores que exercem a prática polivalente é um atributo do êxito da acomodação e da adaptação característica da semiformação. Assim, as possibilidades da construção de uma realidade para a formação estética em harmonia com uma estruturação pedagógica que reflita nas aulas de arte parecem ainda distantes, dado que, para que isso ocorra, é necessário um arranjo sólido capaz de perpassar a formação dos arte-educadores, as estruturas curriculares, a realidade das escolas e o corpo discente.

Depreendemos que as problemáticas do trabalho do arte-educador e do ensino de arte estão factualmente relacionadas às objetividades da sociedade administrada e a seu modo de reificação da vida, dado que as possibilidades de reflexão e reconhecimento intersubjetivo são cada vez mais limitadas. O despertar da crítica pela racionalidade estética não constitui o propósito da organização atual da sociedade. De maneira contrária, espera-se que os indivíduos sejam cada vez mais práticos, competitivos e objetivos; que conheçam e dominem apenas aquilo que serve ao desenvolvimento da indústria, do mercado de trabalho e/ou do mundo globalizado. Assim, não há tempo para (re)pensar a vida, apreciar, analisar, decodificar e interpretar uma obra de arte a partir da experiência estética, muito menos ter a arte como uma possibilidade de renúncia e resistência.

Frente a tais desafios, buscamos construir um pensamento voltado à estética na perspectiva de Adorno, como oportunidade de um olhar diferenciado diante da uniformização desumanizada que tem permeado a organização do ensino de arte no ensino médio. Acreditamos na possibilidade de a perspectiva estética reconquistar o sentido da arte enquanto "antítese social da sociedade" (ADORNO, 2008, p. 21). Pucci (2001, p. 6), refletindo sobre o sentido da educação para Adorno, diz que "numa sociedade danificada, que pode, continuamente, parir manifestações de barbárie, só tem sentido pensar a educação como geradora da autorreflexão". Tal é o que entendemos ser a tarefa da arte enquanto formação estética no ensino médio. 


\section{Considerações finais}

O estudo constituiu uma tentativa de compreender alguns dos desafios dos arte-educadores perante a sociedade administrada e incutir algumas reflexões e proposições do pensamento estético de Adorno, tomando por base o trabalho dos arte-educadores do ensino médio das escolas públicas do Distrito Federal. A leitura crítica de Adorno em torno do projeto da modernidade, refletindo sobre seu progresso e destruição a partir dos ideais de civilização e esclarecimento, bem como seu entendimento acerca da relação desse progresso com a fundamentação da sociedade administrada e suas determinações objetivas, tendo como uma de suas expressões a indústria cultural, foram para nós aportes imprescindíveis a fim de discutir as possibilidades que a arte, em consonância com o trabalho do arte-educador, tem para realizar no enfrentamento da crise de formação cultural que se instaurou. Nas obras de arte autênticas, diferentemente das obras fabris reproduzidas para a identificação imediata, ele observa uma via promissora para se trilhar rumo às condições de emancipação. Diz Adorno (2008, p. 28): "a arte não é unicamente o substituto de uma práxis melhor do que a até agora dominante, mas também crítica da práxis enquanto dominação da autoconservação brutal no interior do estado de coisas vigente e por amor dele". Para ele, a existência da estética na obra de arte autêntica é uma provocação ao pensamento, uma peleja ao reconhecimento do outro, uma leitura inquietante do social em seu tempo e um arquétipo à crítica.

Ao adentrarmos as especificidades dos desafios dos arte-educadores do ensino médio que se destacaram na pesquisa, constatamos que existem entraves importantes que se põem ao trabalho desse profissional. Nossa pesquisa pactua com os estudos prévios no que tange à desvalorização da arte mediante as demais disciplinas do currículo, às problemáticas com o ensino polivalente, às barreiras referentes aos reflexos do mundo, à compreensão e ao interesse dos estudantes. É explícito que a prática de ensino do arte-educador se apresenta fragilizada sob a perspectiva de não corresponder ao seu compromisso com a formação estética e com a crítica social.

Sobre a problemática da polivalência, compreendemos que se trata de uma objeção oriunda de fatores organizacionais do Estado, que não se compromete com a formação estética dos indivíduos. Apesar de os professores serem concursados para vagas pertinentes à sua formação em graduação (que é específica em apenas uma linguagem artística, pois cada linguagem é tratada em um curso de graduação diferenciado), a atuação docente nem sempre se restringe a sua especialização. Os professores de arte assumem uma postura polivalente no intuito de abranger a diversidade dos conteúdos curriculares indicados para a disciplina e também para permitirem aos estudantes a comunicação com as diversas linguagens artísticas. Para isso buscam formações aligeiradas, que reproduzem um modelo instrumental, e não dão conta da intensidade conceitual que contemple o arcabouço formativo dos indivíduos.

O reconhecimento e a busca pela autorrealização intersubjetiva também são desafios postos aos arte-educadores, que não sentem seus trabalhos valorizados pelos estudantes, por seus pares e pela sociedade como um todo. A desvalorização das linguagens da arte de uma forma crítica e reflexiva na sociedade administrada também 
se apresenta como um desafio a esse ensino e é diretamente percebida no trabalho do arte-educador; e, até mesmo por essa razão, muitas vezes os professores levam para a sala de aula produtos da indústria cultural. Devido à objetividade e aos atributos de colaboração ao mercado que esses produtos carregam em si, a crítica e a reflexão acabam por quase inexistirem nesse contexto. Com essa prática, os docentes buscam, de algum modo, fazer com que os estudantes se identifiquem com a disciplina e expressem o almejado reconhecimento à arte e ao trabalho do arte-educador. No entanto, é no embaraço entre a busca do reconhecimento e da autorrealização e também no desejo de proporcionar tal identificação entre a arte e os estudantes que percebemos a adaptação e o reforço das condições da semiformação. Por conseguinte, a realização de experiências e a formação estética e crítica desses estudantes parece se distanciar ainda mais da realidade do ensino de arte. Se as aulas dessa disciplina não estão se valendo da arte autêntica, mas dos produtos da indústria cultural e de sua bagagem reificadora, há então uma impossibilidade maior de o exercício crítico se consumar por essa via. Nessa constatação, podemos perceber quão sorrateira a sociedade administrada é e como ela tem se (re)afirmado no cotidiano escolar por meio de uma cadeia sucessiva de objetividades.

Ante os desafios sabidos no tocante ao trabalho do arte-educador, reafirmamos que o pensamento estético, conhecido na teoria estética de Adorno, é uma importante proposição para o ensino de Arte, que pode ser compreendido desde a formação dos arte-educadores até o ensino da arte no ensino médio. Acreditamos, desse modo, na importância da formação estética, tanto do arte-educador quanto do estudante do ensino médio, no seu sentido crítico, perturbador, decodificador e dotado de aberturas para o outro e para o social, como uma alternativa de que a arte-educação dentro do sistema de ensino não sirva apenas como uma estrutura a transferências de conhecimentos estanques abordados nos sistemas de avaliação, tais como os vestibulares e o Exame Nacional do Ensino Médio (Enem), nem reforce a semiformação artística. Estimamos que, em uma perspectiva estética, conforme apontado por Adorno, a arte se coloque como um espaço de formação para o espírito humano, em que a sensibilidade crítica não esteja contra a ciência, mas vislumbrada como pertencente à integralidade do indivíduo e como forma de resistência aos tempos de crise. Segundo Pucci (2016, p. 155):

É preciso fecundar os conhecimentos técnicos e as habilitações profissionais com o tempero da autorreflexão crítica e criar condições para que o educando apreenda realmente o sentido e as perspectivas de crescimento humano e social presentes no domínio de sua especificidade, bem como para que ele desenvolva a capacidade de considerar essas forças formativas no contexto de suas inquietações vivas e em tensão com as questões econômicas, sociais, culturais e políticas que interferem em seu dia a dia.

Transcender as perspectivas teóricas à prática transformadora aos desafios dos arte-educadores é uma tarefa que requer exercício crítico na busca por caminhos que nos permitam reagir à reificação que se impõe à educação e à formação dos sujeitos. Por isso a estética, enquanto outra perspectiva de racionalidade, permite-nos refletir à luz da arte as condições da vida e da sociedade e nos parece uma proposta possível. 
Nesse sentido, acreditamos na possibilidade de o arte-educador desenvolver um espírito crítico capaz de desvelar o caráter instrumental do seu trabalho e se questionar de modo mais reflexivo sobre as problemáticas vivenciadas em sua atuação de educador artístico. Diante de tais considerações, entendemos que o arte-educador, alicerçado em uma formação estética e crítica, pode se colocar como um agente transformador de seu tempo e formador não apenas de sujeitos para o mundo do trabalho, mas de espíritos mais críticos, autônomos e humanizados.

\section{Referências}

ADORNO, Theodor W. Educação e emancipação. São Paulo: Paz e Terra, 1995.

ADORNO, Theodor W. Teoria da semicultura. Tradução de Newton Ramos de Oliveira, Bruno Pucci e Cláudia de Moura Abreu. Educação \& Sociedade, Campinas, n. 56, 1996.

ADORNO, Theodor W. Teoria da Semiformação. In: PUCCI, Bruno; ZUIN, Antônio Á. S.; LASTÓRIA, Luiz A. C. N. Teoria Crítica e inconformismo: Novas perspectivas de ensino. Tradução de Newton Ramos-de-Oliveira. Campinas, São Paulo: Autores Associados, 2010. p. 6-40.

ADORNO, Theodor W. Teoria estética. Tradução de Artur Morão. Lisboa, Portugal: Edições 70, v. 14, 2008. (Coleção Arte \& Comunicação).

ADORNO, Theodor W.; HORKHEIMER, Max. Dialética do esclarecimento: fragmentos filosóficos. Tradução de Guido António de Almeida. Rio de Janeiro: Zahar, 1985.

BARBOSA, Ana Mae. Arte-Educação no Brasil: realidade hoje e expectativas futuras. Estudos avançados, São Paulo, v. 3, n. 7, p. 170-182, dez. 1989. Disponível em: <https://tinyurl.com/ y6u9zw4k>. Acesso em: 3 dez. 2017. http://dx.doi.org/10.1590/S0103-40141989000300010.

BRASIL. Ministério da Educação. Conselho Nacional de Educação / Câmara de Educação Superior. Diretrizes curriculares nacionais do curso de graduação em artes visuais. Brasília: MEC, 2007.

CASTRO, Rosana de. Os incomodados que se desloquem: problematizando o ensino das artes visuais. Revista Digital do LAV, [S.1.], n. 11, p. 047-058, set. 2013. ISSN 1983-7348. Disponível em: <https://periodicos.ufsm.br/revislav/article/view/10726>. Acesso em: 20 jan. 2018. DOI: http://dx.doi.org/10.5902/1983734810726.

CAZDEN, Courtney. B. A pedagogy of multiliteracies: designing social futures. Harvard Educational Review, Spring, v. 66, n. 1, p. 61-93, April 1996. DOI: http://dx.doi.org/10.17763/ haer.66.1.17370n67v22j160u.

CENCI, Angelo V.; DALBOSCO, Claudio A.; MUHL, Eldon. H. Reconhecimento e formação. In: BOMBASSARO, Luiz Claudio; DALBOSCO, Claudio A.; HERMANN, Nadja (Orgs.). Percursos hermenêuticos e políticos: homenagem a Hans-Georg Flickinger. Porto Alegre: Pontifícia Universidade Católica do Rio Grande do Sul, 2014.

CONTE, Elaine. Tempo e performance no trabalho docente. Educação(UFSM), Santa Maria, p. 541-552, nov. 2014. ISSN 1984-6444. Disponível em: <https://periodicos.ufsm.br/reveducacao/ article/view/14250>. Acesso em: 3 dez. 2017. DOI: http://dx.doi.org/10.5902/1984644414250.

DUARTE JÚNIOR, João Francisco. Por que arte-educação? 22. ed. São Paulo: Papirus, 2012. (Coleção Ágere).

FARINA, Cynthia; ALBERNAZ, Roselaine Machado. Arte y vida en Deleuze. Formación estética y políticas de lo sensible. Educação (UFSM), Santa Maria, p. 113-122, abr. 2017. ISSN 1984-6444. Disponível em: <https://tinyurl.com/y9jhdwo5>. Acesso em: 3 dez. 2017. DOI: http://dx.doi.org/10.5902/1984644418539. 
FERRAZ, Maria Heloísa C. de T. Arte na educação escolar. 4. ed. São Paulo: Cortez, 2010. FUSARI, Maria F. de Rezende e; FERRAZ, Maria Heloísa C. de T. Arte na educação escolar. Cortez, 2001.

GADAMER, Hans-Georg. Hermenêutica como filosofia prática. In: GADAMER, Hans Georg. A razão na época da ciência. Tradução de Ângela Dias. Rio de Janeiro: Tempo Brasileiro, 1983.

HONNETH, Axel. Luta por reconhecimento: a gramática moral dos conflitos sociais. São Paulo: 34, 2003.

MAGALHÃES, Ana Del Tabor Vasconcelos. Ensino de arte: perspectivas com base na prática de ensino. In: BARBOSA (ORG.), A. M. Inquietações e mudanças no ensino da arte. São Paulo: Cortez, 2002.

NEUVALD, Luciane; GUILHERMETI, Paulo. A semiformação no curso de Pedagogia: uma reflexão introdutória. In: Seminário Nacional de Filosofia \& Educação. Santa Maria. Confluências. Santa Maria: Facos, 2006. Disponível em: <http://coral.ufsm.br/gpforma/2senafe/ PDF/026e4.pdf> Acesso em: 2 jan. 2018.

PIMENTEL, Lucia Gouvêa. Tecnologias contemporâneas e o ensino da arte. In: BARBOSA, Ana Mae (Org.) Inquietações e mudanças no ensino de arte. 7. ed. São Paulo: Cortez, p. 113121,2012

PUCCI, Bruno. Teoria crítica e educação: contribuições da teoria crítica para a formação do professor. Espaço Pedagógico, v. 8, p. 13-30, 2001.

PUCCI, Bruno. O privilégio da experiência filosófica no processo educacional. Comunicações, Piracicaba, v. 23, n. 3, p. 145-155, 2016.

PUCCI, Bruno. A escola e a semiformação mediada pelas novas tecnologias. In: PUCCI, Bruno; ALMEIDA, Jorge de; LASTÓRIA, Luiz Antônio Calmon Nabuco (Orgs.). Experiência formativa e emancipação. São Paulo: Nankin, 2009. p. 69-80.

TOURINHO, Irene. Transformações no ensino da arte: algumas questões para uma reflexão conjunta. In: BARBOSA, Ana Mae (Org.). Inquietações e mudanças no ensino da arte. 7. ed. São Paulo: Cortez, 2003. p. 28-36.

TREVISAN, Amarildo. Filosofia da educação: mímesis e razão comunicativa. Ijuí: Unijuí, 2000 .

\section{Notas}

${ }^{1} \mathrm{O}$ uso do termo "arte-educador" é oriundo do movimento Arte-Educação ocorrido no Brasil no final da década de 1970, inspirado nas premissas da Nova Escola. Segundo Ferraz (2010, p. 19) “a arte-educação vem-se apresentando como um movimento em busca de novas metodologias de ensino e aprendizagem nas escolas. Revaloriza o professor da área, discute e propõe um redirecionamento do seu trabalho, conscientizando-o da importância da sua ação profissional e política na sociedade”.

${ }^{2}$ O Currículo em Movimento do Ensino Médio da Secretaria de Estado de Educação do Distrito Federal foi elaborado por especialistas da educação de modo colaborativo a fim de atender a meta do Plano Nacional de Educação (PNE) para o decênio de 2011 a 2020. Está sistematizado dentro da perspectiva da Pedagogia dos Multiletramentos (CAZDEN et al., 1996) e estabelece-se dentro de quatro áreas do conhecimento: Linguagens, Matemática, Ciências da Natureza e Ciências Humanas. Os conteúdos que abrangem o ensino de arte estão contemplados de modo mais ostensivo, dentro da área das Linguagens.

${ }^{3}$ Palavra oriunda do vocabulário alemão que significa "formação". Dentro da tradição filosófica alemã, é compreendida como formação cultural e/ou formação do espírito. 
* Doutoranda em Educação pelo Programa de Pós-Graduação em Educação da Universidade de Brasília, Brasília, Distrito Federal, Brasil.

** Professora associada do programa de Pós-Graduação em Educação da Faculdade de Educação da Universidade de Brasília, Brasília, Distrito Federal, Brasil.

\section{Correspondência}

Catia Piccolo Viero Devechi - Universidade de Brasília, Faculdade de Educação. Campus Darcy Ribeiro, Asa Norte. CEP: 70910900. Brasília, Distrito Federal, Brasil.

E-mail: ellaella68@gmail.com - catiaviero@gmail.com

Recebido em 11 de abril de 2018

Aprovado em 16 de julho de 2018

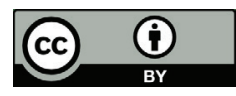

This work is licensed under a Creative Commons Attribution 4.0 International (CC BY 4.0). 